\title{
ENSINO TÉCNICO: UMA NECESSIDADE OU UMA FALÁCIA? NOTAS PARA A COMPREENSÃO DA FILOSOFIA DO ENSINO TÉCNICO EM PORTUGAL E NO BRASIL
}

\author{
Luís Alberto Marques Alves \\ Universidade do Porto, Portugal.
}

\section{$\cos 8$}

Resumo

Falar de ensino técnico obriga a cruzar vertentes científicas diversas - história, sociologia, economia e contextualizar a informação no âmbito da História da Educação. A herança recebida do sistema corporativo, a partilha de responsabilidades entre público e privado, as expectativas sociais e económicas, a sua relação com o desenvolvimento e a difícil relação entre o nacional e o internacional são algumas das vertentes que importa analisar quando procuramos fazer um trajeto breve na dimensão mais alargada no tempo. Inserir ainda uma preocupação comparativa entre Portugal e Brasil, ainda que pontual, exige uma síntese das ideias nucleares marginalizando o acessório. Procura este artigo, numa cronologia que vai do século 18 aos fins do 20, elencar as mudanças de filosofia, de investimento, de credibilidade social e de necessidade económica.

Palavras-chave: ensino técnico, profissionalização, capitalismo industrial, neoprofissionalismo, Portugal, Brasil, ensino secundário.

\section{TECHNICAL TEACHING: A NECESSITY OR A FALLACY? NOTES FOR THE COMPREHENSION OF THE PHILOSOPHY OF TECHNICAL TEACHING IN PORTUGAL AND BRAZIL}

\section{Abstract}

To talk about technical teaching forces us to cross several scientific fields - history, sociology, economy - and to contextualize the information regarding the History of Education. The inheritance received from the corporative system, the share of responsibilities between public and private, the social and economical expectations, its relation with development and the difficult relation between national and international are some of the fields that we must analyse when we aim to create a path brief in its dimension but stretched in time. To also insert a comparative concern between Portugal and Brazil, even if punctual, demands a synthesis of the nuclear ideas marginalizing the accessory. 
This article aims to, in a chronology going from the 18 century to the late 20th, specify the changes in the philosophy, in the investment, in the social credibility and in the economical necessity.

Key-words: technical teaching, professionalization, industrial capitalism, neoprofessionalism, Portugal, Brazil, secondary teaching.

\section{ENSEÑANZA TÉCNICA: UNA NECESIDAD O UNA FALACIA? NOTAS PARA LA COMPRENSIÓN DE LA FILOSOFÍA DE LA ENSEÑANZA TÉCNICA EN PORTUGAL Y EN BRASIL}

\section{Resumen}

Hablar de enseñanza técnica obliga a cruzar vertientes científicas diversas - historia, sociología, economía - y a contextualizar la información en el ámbito de la Historia de la Educación. La herencia recibida del sistema corporativo, la partición de responsabilidades entre público y privado, las expectativas sociales y económicas, su relación con el desarrollo y la difícil relación entre el nacional y el internacional son algunas de las vertientes que importa analizar cuando buscamos hacer un trayecto breve en la dimensión pero ampliado en el tiempo. Insertar aún una preocupación comparativa entre Portugal y Brasil, aunque puntual, exige una síntesis de las ideas nucleares marginalizando el accesorio. Pretende este artigo, en una cronología que va del siglo 18 a fines del 20, especificar los cambios de filosofía, de embestida, de credibilidad social y de necesidad económica.

Palabras-clave: enseñanza técnica, profesionalización, capitalismo industrial, neoprofesionalismo, Portugal, Brasil, enseñanza secundaria.

\section{L'ENSEIGNEMENT TECHNIQUE: UNE NECESSITE OU UNE ERREUR? ASPECTS POUR LA COMPREHENSION DE LA PHILOSOPHIE DE L'ENSEIGNEMENT TECHNIQUE AU PORTUGAL ET AU BRESIL}

\section{Résume}

En parlant de l'enseignement technique on nécessite d'indiquer plusieurs aspects scientifiques histoire, sociologie, économie - et de contextualiser l'information dans l'histoire de l'éducation. L'héritage du système d'entreprise, la répartition des responsabilités entre les attentes de l'état et des privés, sociaux et économiques, leur relation avec le développement et les relations difficiles entre le national et l'international sont quelques-uns des aspects qui doivent être considérés lors de la recherche pour faire un chemin en bref dimension, mais étendu dans le temps. Avoir également une préoccupation comparative entre le Portugal et le Brésil, bien que parfois, nécessite une synthèse des idées de marginaliser accessoire nucléaire. Recherche à cet article, dans une chronologie qui va du $18^{\text {ème }}$ siècle à la fin du $20^{\text {ème }}$ siècle, la liste des changements dans la philosophie, l'investissement, la crédibilité sociale et une nécessité économique.

Mots-clé: enseignement technique, professionnalisation, capitalisme industriel, neoprofessionnalisme, Portugal, Brésil, enseignement secondaire. 


\section{Introdução}

Se é verdade que foi a crença nos benefícios dos ensinos técnico e profissional sobre a economia e sobre o emprego que mais sustentou as políticas que o suportaram e o fizeram crescer, nomeadamente quando os governos perfilharam as teorias funcionalistas e, em particular, a teoria do capital humano, também é no âmago dessa relação entre a educação e a economia que se encontram alguns dos principais pressupostos da falácia do ensino profissional para regressar à expressão de Philip Foster. (Azevedo, 200, p. 81) ${ }^{1}$

$\mathrm{O}$ ensino técnico, considerado nas diversas vertentes profissionalizantes agrícola, industrial, comercial, serviços - tem sido objecto de estudo, tanto na área da sociologia da educação, como na da sociologia do trabalho. Paralelamente tem sido enfatizado historicamente dentro do arco temporal da construção da escola e, em particular, da implementação do Estado Moderno.

Estes diferentes enfoques mostram, antes de tudo, a multiplicidade de perspetivas, mas, simultaneamente, a complexidade analítica resultante dos diferentes contributos, inter e transdisciplinares. Desde logo, o contributo sociológico obriga-nos a inserir este subsistema dentro das funções chave da escola, que tem o papel de integrar os alunos no contexto social e de diferenciar para poder cumprir o papel específico que a sociedade thes tem destinado. Os códigos culturais que transmite são nucleares para garantir a coesão social, a participação cívica, em suma a defesa da ordem estabelecida. A qualificação, enquanto recursos humanos, permite o fornecimento ao mercado laboral de profissionais capazes de garantirem a expansão económica.

Em termos históricos sabemos que em épocas de expansão e de grandes alterações tecnológicas solicitou-se sempre à escola, ao sistema educativo, que preparasse esses exércitos de técnicos qualificados e peritos profissionais para poderem alimentar 0 crescimento. Mas quando a retração ou a crise se apoderou das estatísticas económicas, sempre se reequacionou o papel deste subsistema, embora sempre se fosse aceitando que continuava a ser a escola o espaço de requalificação, em função das novas prioridades ditadas pelo poder político.

Esta aparente contradição - entre a urgência das mudanças económicas e a lentidão das alterações ou dos resultados educativos - forneceu tema para os debates políticos, para as discussões pedagógicas, para as relações entre a escola e a economia e, correlativamente, para a definição do papel do ensino técnico nesse contexto volátil de ideias e mudanças.

Centrando-nos no conteúdo mais estável, vamos procurar, no tempo longo dos séculos 19 e 20, identificar os principais marcos que caraterizaram o percurso do ensino técnico, sobretudo em Portugal, mas incorporando algumas referências ao ensino médio profissionalizante brasileiro, desde os finais do século 18 aos finais do século 20. Esta

${ }^{1}$ O autor se refere a Foster (1978). 
grande distância temporal leva-nos dos seus fins assistenciais, quando se procurava garantir a reinserção pela qualificação ou profissionalização, até à sua descaracterização face ao neoprofissionalismo contemporâneo. Entre um e outro momento ficam as palavras, as ideias, as funções que historicamente lhe foram atribuídas num quadro em que quase sempre 0 Estado decidiu muito, dialogou ou partilhou pouco e sempre procurou ter a primeira e última palavras.

\section{Da extinção das corporações à ação do Estado}

A cada ofício correspondia uma corporação, a cada corporação o seu estatuto, ou regimento [...] ou seja o conjunto de leis privadas que regulamentava cada ofício. [...] Se a especificidade era a base da diferenciação inter-ofícios, a posse da arte dividia internamente mestres, oficiais e aprendizes. Toda a forma de arte carece duma iniciação. Desde cedo, o exame de mestria é decisivo para a passagem de oficial a mestre [...] e a aprendizagem irá sendo cada vez mais regulamentada ao longo do tempo. (Pereira, 1988, p. 45)

Este pressuposto é importante porque, em certos países, a força do sistema corporativo garantiu, durante muito tempo, uma formação adequada e certificada sem qualquer intervenção da parte do Estado. Aliás, no liberalismo, a força significativa de que as corporações dispunham em termos sociais e de influência política obrigou a que se fosse adiando a sua extinção, apenas formalizada em 7 de maio de 1834 . O caso francês é, por exemplo, muito idêntico ao nosso uma vez que

la disparition brutale et effective de ce quadre réglementaire coutumier a livre à la seule loi de l'offre et de la demande la régulation de la formation professionnelle des jeunes et des conditions de leur embauche, provoquant ce qui a été appelé tout au long du $19 \mathrm{e}$ siécle une crise de l'apprentissage. (Troger, 2006, p. 75-76)

A ausência do sistema de aprendizagem profissional garantido pelas corporações, a par da libertação do trabalho, implica a criação de alternativas, numa altura em que o Estado Nação tendia a estender cada vez mais os seus tentáculos - funções - e que germinava a ideia da imprescindível articulação entre educação, trabalho/profissão, progresso e criação de riqueza. Longe vem ainda o tempo da desmitificação desta relação funcionalista. Evidentemente que outros países apostaram em vias de menor dependência relativamente ao Estado: na Alemanha, na Inglaterra, na Itália ou na Dinamarca a grande maioria dos operários e dos empregados assalariados passaram a ser formados pelas empresas ou em locais em perfeita ligação com elas. A escolarização massiva das formações profissionais e técnicas dos jovens no sistema educativo público foi uma opção portuguesa - e francesa, por exemplo -, mas não constitui a regra geral.

Esta especificidade obriga-nos, no entanto, a focalizar o papel que o poder político vai ter no quadro da alternativa formativa e profissionalizante. Apesar de algumas iniciativas no final do século 18 protagonizadas pelo marquês de Pombal - nomeadamente a preparação 
de comerciantes mais actualizados e técnicos industriais mais capazes -, só depois da instauração definitiva do Liberalismo e da extinção das corporações (1834) se assiste a uma sequência de medidas globalmente articuladas no sentido dessa formação alternativa ao sistema corporativo.

Há ideias-chave que ressaltam e que se assumem como caraterizadoras do percurso realizado, demonstrando a consciência do papel que o ensino industrial, e técnico em geral, poderia e deveria desempenhar no contexto nacional.

A primeira passa pela necessidade de incutir uma maior vitalidade no desenvolvimento económico por meio de iniciativas escolares que visassem à preparação de quadros na indústria, na agricultura e no comércio. As iniciativas de finais do século 18, na área do ensino comercial, evidenciam a priorização da circulação de mercadorias sobre a sua produção. É claramente a tentativa de salvaguardar espaços, de aumentar a qualidade de serviços comerciais, de rentabilizar produtos e de aproveitar a nossa marginalidade beligerante para equilibrar despesas e receitas públicas. Ao realçarmos as iniciativas da Aula do Comércio ou as generosas medidas de Pina Manique de introduzir o trabalho manual nas escolas primárias, o trabalho físico e o ensino da indústria na Casa Pia, queremos evidenciar que o País produtivo ficou à mercê da suficiência dos técnicos estrangeiros que nos visitaram nos finais de setecentos e nos inícios do século 19, assim como ficou à espera de que o Liberalismo trouxesse uma nova visão do investimento educativo capaz de formar operários especializados nas diferentes actividades económicas. A lentidão exasperante da instauração do Liberalismo em Portugal protelou, primeiro para 1836 e mais tarde para 1852, as iniciativas consistentes, deixando para 1884 o alcance mais alargado da rede escolar industrial. Paralelamente, como destacamos, a extinção das corporações acabou com uma estrutura formativa e de aprendizagem que funcionou durante séculos.

A segunda está intimamente relacionada com esta necessidade de uma rede escolar coerente, lógica e eficaz, para substituir esses espaços de formação e regulamentação. Apesar de o Estado ter herdado essa nova função, as iniciativas que institucionalizam a criação de escolas não têm o impacto desejado porque, para além de nem sempre funcionarem - a realidade fica sempre além da norma - algumas são mesmo encerradas por falta de alunos; falta-lhes também um espírito de orientação comum. Esta ausência passa pela falta de um Ministério da Instrução, duradouro e não episódico, capaz de promover a articulação vertical e horizontal do sistema de formação. Vertical pela introdução da instrução primária como habilitação mínima para o ingresso na escola técnica, ou pela incorporação do trabalho manual no primeiro ciclo de aprendizagem e pela aceitação do papel especializante que os institutos industriais e comerciais podiam desempenhar. Horizontal pelo papel dinamizador que deveria desempenhar na celebração de protocolos com empresas privadas ou estatais no sentido de conferir uma prática adequada aos alunos, futuros operários dos diversos sectores económicos.

A iniciativa de Fontes Pereira de Melo, em 1852, criando o ensino industrial, clarificando o papel dos institutos e certificando o significado social da frequência dos diferentes graus de ensino, assume-se como o arranque de um processo que esperava do Estado um papel mais dinamizador e coordenador. Coube quase sempre ao Ministério das Obras Públicas, 
Comércio e Indústria o papel motor nessas iniciativas, numa altura em que os grandes investimentos eram, sobretudo, canalizados para a criação de infraestruturas ferroviárias, rodoviárias e portuárias.

A terceira ideia passa, forçosamente, pela crescente preocupação em olhar para o mundo com os pés bem assentes na nacionalidade. Desde logo, em 1864, quando João Crisóstomo de Abreu e Sousa estabeleceu as primeiras escolas industriais nas localidades que mais carentes se mostravam de operários especializados - Covilhã, Portalegre e Guimarães - salvaguardando a possibilidade de surgirem outras "nas mais terras do reino que, pela sua importância fabril carecerem delas" (Arroyo, 1911, p. 5). Depois quando em 1884 António Augusto de Aguiar, visando complementar os papéis dos museus e das escolas, defendeu que "as escolas criadas junto dos Museus ficarão dentro dos seus recintos, subordinadas às suas respectivas direcções; os cursos terão um carácter útil e nacionalista, inspirando-se no nosso folk-lore; e as direcções dos Museus procurarão estabelecer prelecções ou cursos industriais livres, relacionados com os seus fins em geral" (Ibid., p. 12). No mesmo sentido, Emídio Navarro, em 1886, legislando pela primeira vez sobre o ensino profissional feminino, incentivou o ensino do fabrico das rendas de bilros na escola de Peniche. A organização do ensino decretada nos anos 1890, sobretudo a de 1891 e 1893, defendeu que uma das funções das escolas industriais era "promover a organização de cursos elementares profissionais das pequenas indústrias locais" (Ibid., p. 23). A primeira década do século 20 não trouxe alterações a este quadro de articulação entre o espaço português e o mundo.

Estas ideias que cruzam transversalmente as iniciativas legislativas de oitocentos, coexistem com manifestações de tristeza face à incapacidade formativa do ensino, nomeadamente industrial. Para uns a responsabilidade deve ser atribuída à pouco exigente burguesia nacional:

Para a indústria portuguesa não existem, por assim dizer, os mercados externos; nós não constituimos aquilo que se chama uma nação industrial. E, quanto ao nosso mercado interno, pode também dizer-se que a concorrência desapareceu, já por causa das suas diminutas proporções, já em virtude da pauta protectora, em casos vários proibitiva, e ainda de outras circunstâncias do nosso meio económico e financial. Compreende-se, pois, que a indústria portuguesa nenhumas ou quase nenhumas reclamações fizesse ao Estado em matéria de ensino profissional. Bastava-lhe a pauta protectora para viver comodamente. (Arroyo, 1911, p. 17)

Para outros, de uma forma mais coerente com o desenvolvimento interno do sistema, as razões deviam ser procuradas nas fragilidades legislativas dos diferentes diplomas. Uma das mais referidas desemboca nos docentes das escolas:

Em Portugal não tratamos de formar o pessoal docente: não fundamos o ensino normal. Vieram do estrangeiro professores de diferentes proveniências e de escolas diversas, mas não estabeleceram a escola normal, donde pudessem sair os futuros professores portugueses. Foram colocados em várias escolas industriais, onde professam o ensino que trouxeram do seu 
país, numa completa e quase geral arbitrariedade e falta de conexão, pedagógica e utilitariamente considerada. Por isso não nacionalizamos a instrução industrial, nem as indústrias de arte. (Colecção, 1899, p. 820)

Outro aspecto insistentemente referido passa pela impossível distância entre a escola e a empresa ou entre o Estado e a iniciativa particular:

No interesse, pois, do fomento nacional, convém estimular as iniciativas particulares, levando-as a melhor compreender a importância da escola industrial e comercial como instrumento de trabalho, a formular previamente as suas exigências nesse sentido e a exercer as funções dirigentes do ensino técnico na escola industrial. (lbid., p. 820)

O tipo de professor e o conceito de escola eram fundamentais pela consciência que se tinha da realidade sócio-económica de finais do século 19, que implicava a formação de operários com determinadas características:

O ensino profissional tem de formar duas classes de operários: a dos que trabalham segundo as condições actuais da localidade, conforme às normas e tipos de produção correntes e julgados bons; e a daqueles, cuja mão de obra deverá ser diversa, mais perfeita ou mais completa do que na actualidade se realiza. No primeiro caso, poderemos encontrar, entre nós mestres hábeis; no segundo, pelo contrário, será necessário procurá-los nos países em que a respectiva mão de obra estiver mais adiantada. (Ibid., p. 821)

A alteração constante de conteúdos programáticos e as deficientes instalações figuram, também, como fatores justificativos da menor produtividade nacional do sistema educativo industrial:

Até hoje entre nós não se tem ligado a devida importância ao problema da construção da casa ou oficina escolar, problema que noutras nações se acha regulamentado, compreendendo a iluminação, o aquecimento, a ventilação, a cubagem de ar, a higiene do mobiliário, os exercícios higiénicos, as comodidades do aluno, etc. (lbid., p. 822)

Culminando esta pirâmide de dificuldades, estava a questão da certificação social da habilitação adquirida. A proliferação de cursos e de escolas, estatais ou particulares, esbarrava num mercado de trabalho com uma caraterização socio-profissional précapitalista. Daí que uma das preocupações omnipresentes nas iniciativas legislativas fosse a das "garantias e vantagens a dar aos alunos das escolas industriais, no intuito de aumentar a frequência escolar, afeiçoar o aluno à escola e prende-lo ao país, depois de terminados os seus estudos". (Ibid., p. 820)

Inventariadas as razões internas ou externas que impediam um efectivo aproveitamento da rede escolar existente em finais do século 19, havia que dar um enquadramento científico à análise, garantindo que as propostas resultantes de uma eficaz inventariação permitisse inflectir ou criar caminhos, corporizando soluções consensuais. É esta a perspectiva do 
Plano de inquérito, técnico e económico, para a remodelação do ensino industrial e comercial, lançado em finais de $1898^{2}$.

Apesar das múltiplas críticas que esta iniciativa levantou e da ausência de resultados pela incapacidade de funcionamento da equipa responsável, os aspetos identificados como essenciais para uma efetiva alteração no sistema educativo industrial, mostram-nos a consciência dos principais problemas de que padecia na altura da implantação da República e ajudam-nos a compreender as reformas que rapidamente se tiveram de corporizar ${ }^{3}$ para romper com a inércia e recuperar o atraso de que o País dava mostras, apesar da multiplicidade de iniciativas desde 1759 a 1910.

Neste delineamento rápido de algumas das ideias presentes ao longo do século 19, é clara a defesa de teorias que ancoravam o incremento dos modernos modelos de educação escolar no industrialismo crescente. Assumia-se como evidente o modo de produção capitalista e cabia às iniciativas estatais na área educativa potenciar a formação da mão de obra necessária ao modo de desenvolvimento capitalista. Nesta óptica, escola de massas, sociedade industrial e economia de mercado deviam caminhar paralelamente e com fins complementares, ou pelo menos devidamente articulados. As interpretações posteriores, em particular das teorias marxistas, a escola como forma de reprodução das relações sociais de produção, ou institucionalistas, J. Meyer e F. Ramírez (1992), por exemplo, vieram amenizar esta relação tão directa, tão funcionalista, mas, como é lógico, não vieram a tempo de interferir na forma como se pensava a escola em geral e a técnica em particular no período oitocentista.

Naturalmente, com o atraso inerente a uma independência recente (1822) e à existência do trabalho escravo durante mais de três séculos, no Brasil foi menos visível, neste período, século 19 e inícios do 20, a preocupação de formar mão-de-obra para um sistema económico de capitalismo industrial e financeiro. A prioridade teve de ser a escolaridade básica regular, embora seja importante referir aqui que só com a Constituição de 1934, elaborada durante a ditadura de Getúlio Vargas, se instituiu o ensino primário obrigatório $^{4}$, reservando-se a formação profissional para fins predominantemente assistencialistas. Em meados da década de 1840, por exemplo, foram construídas dez casas de educandos e artífices em dez capitais de províncias, com o objectivo de "diminuição da criminalidade e da vagabundagem" (Cordão, 2005, p. 44). Na década seguinte, o governo "criou estabelecimentos especiais para abrigar os menores abandonados e órfãos, os chamados asilos da infância e dos menores desvalidos" (Cordão, 2005, p. 44). Esta vertente assistencialista manteve-se até 1906, altura em que o ensino profissional passou a ser atribuição "não mais dos órgãos de assistência social e de protecção aos e menores

\footnotetext{
${ }^{2}$ Trata-se do plano criado pelo decreto de 24 de novembro de 1898.

${ }^{3}$ Referimo-nos, por exemplo, ao decreto n. 5.029, de 1ำ de dezembro de 1918, sobre a organização do ensino industrial e comercial, da iniciativa do secretário de Estado João Alberto Pereira de Azevedo Neves, e cujo relatório justificativo utilizamos e citamos neste artigo.

${ }^{4}$ Mesmo com essa instituição, reiterada na revisão constitucional de 1937, havia várias ressalvas para o seu incumprimento: a contribuição financeira solidária das famílias e a isenção de obrigatoriedade quando não houvesse escolas próximas ou quando os pais fossem muito pobres. Aliás, ressalvas idênticas ao que foi ocorrendo na legislação portuguesa, tanto no século 19 como mesmo no 20.
} 
abandonados, mas sim do Ministério da Agricultura, Indústria e Comércio". (Cordão, 2005, p. 45). Na primeira década do século 20 são já múltiplas as iniciativas que associam a formação de mão-de-obra ao desenvolvimento dos setores produtivos e criam uma rede de escolas de aprendizes e artífices em várias regiões do país. Foi, sobretudo em 1910, com o presidente da República Nilo Peçanha, que se criaram essas escolas "voltadas mais para a área industrial [...] tornando-se o primeiro passo efectivo para a implantação de uma rede federal de educação profissional no Brasil" (Cordão, 2005, p. 45).

\section{Da expectativa funcionalista à formação mais globalizada}

O século 20 vai trazer-nos novas formas de equacionar o papel do ensino técnico no quadro das alterações tanto nos setores produtivos, quanto na área das qualificações, quer ainda do papel que os Estados podem e devem ter na interseção dos vetores anteriores.

Olhando para os setores ditos produtivos, surgiram novos modelos de desenvolvimento nacional, genericamente caraterizados como fordismo, neofordismo e pós-fordismo. Consoante o nível em que cada país se encontrava, assim teremos necessidade de um determinado tipo de profissionalização, sendo certo que à medida que avançamos para graus de desenvolvimento mais próximos de nós, mais necessidade temos de problematizar os conteúdos da formação, de equacionar o papel do ensino secundário em correlação com o ensino técnico, de selecionar os conteúdos que devem ser atribuídos a cada um, ou até, no limite, decidir se haverá necessidade de existirem os dois subsistemas.

O período entre as duas guerras mundiais e a fase posterior à segunda até aos inícios dos anos 1970, foi uma época de grande desenvolvimento, de solicitação permanente de mão-de-obra qualificada para os diferentes setores, de alterações dos conteúdos, muitas vezes indexados às alterações tecnológicas, e de um papel quase exclusivo da iniciativa estatal, ou pelo menos da sua supervisão para garantir a credibilidade da certificação. No último quartel do século 20, sobretudo, esse papel deu lugar a uma visão mais global dos sistemas educativos, com a criação de indicadores internacionais que passaram a legitimar externamente os novos enfoques, os novos currículos e até os novos conteúdos.

Dois aspetos parecem-nos importantes para perspetivar a realidade portuguesa, e até a brasileira, ao longo do século 20. Primeira: enquanto o conceito de Estado-nação prevalecer, ou sempre que ele se assuma numa vertente interventiva, senão mesmo exclusiva, as políticas educativas andarão próximas dos "benefícios económicos específicos da educação, através de uma rápida expansão da teoria do capital humano" (Hufner; Meyer; Naumann, 1992, p. 348). Segunda: quando esse conceito sofrer desenvolvimentos no sentido da sua modernização, mesmo que em conflito com o paradigma do mundo único e interdependente ou com o conceito de uma nova ordem económica mundial, os sistemas educativos passarão, sobretudo, a assumir-se como "um factor crucial do progresso nacional e da igualdade entre as nações" (Hufner; Meyer; Naumann, 1992, p. 393) perdendo aí espaço as decisões internas, pressionadas pelas referências internacionais de organizações científicas credíveis.

Assim enquadrado, importa agora verificar como na prática as mudanças se corporizaram, para já entre a 1ª República e o fim do Estado Novo. 
Nos inícios do século 20 reitera-se a profissão de fé na função do sistema educativo acreditando que "na escola técnica está a força, o direito e o futuro de um povo", embora se comece também a falar na necessidade de uma "maior plasticidade da sua organização"6. Mantém-se claramente a ideia que havia necessidade de se formarem produtores para 0 tecido operário industrial de forma a garantirmos a produção de riqueza que nos aproximasse dos países mais desenvolvidos, mas começa a associar-se o conceito de trabalho físico ao intelectual:

É necessário dar à classe operária o que lhe é devido, mas é indispensável primeiro que tudo instrui-la convenientemente [...]; o progresso tem uma unidade social, um factor elementar que é o operário, quer seja o operário de mãos calejadas em trabalhos rudes, quer seja o operário que despende as suas horas em pesquisas científicas ${ }^{7}$. (Diário do Governo, n. 263, 1947, p. 809)

Se, por um lado, pretendia-se uma resposta eficiente às críticas que continuavam a ser veiculadas, sobretudo por pessoas ligadas à indústria, por outro era visível a preocupação em reordenar a rede e em introduzir uma nova filosofia no pensamento sobre o ensino técnico:

Já em plena 1a República, a deficiente formação dos recursos humanos, ocupados na indústria, continua a ser notada e a constituir um dos obstáculos colocados à industrialização. O eng. José de Oliveira Simões, geralmente bem informado sobre as questões industriais retratava assim a situação: a falta de instrução geral e especial explica a deficiência que se nota nas nossas oficinas, quanto a pessoal dirigente. Embora a tendência seja para diminuir o défice nacional, o pessoal de mestres e contramestres é em grande parte estrangeiro. (Rodrigues, 1999, p. 274)

A reforma de 1918, de Azevedo Neves, ao procurar dar resposta a estas críticas, reordenou a rede, alterou a função do ensino técnico, dissuadiu as matrículas nos liceus, facilitou o recrutamento de professores, ouviu com mais frequência interlocutores - tanto do setor económico como do educativo ${ }^{8}$ - e ampliou a rede de escolas técnicas, que passou de 30 para cerca de 50 durante a $1^{a}$ República.

Os números ajudam-nos a perceber que a população escolar passou a considerar a importância da frequência do ensino técnico, mesmo existindo socialmente um grande desfasamento entre a dignidade do Liceu e a da Escola Técnica.

\footnotetext{
${ }^{5}$ Relatório da reforma do ensino técnico de 1ํ de dezembro de 1918.

${ }^{6}$ Relatório da reforma de 24 de dezembro de 1901.

${ }^{7}$ Relatório da reforma de 1918.

${ }^{8} \mathrm{Na}$ sequência desta reforma foi criada a Associação dos Professores das Escolas Industriais e Comerciais Apeic -, que passou a ser um interlocutor com influência nas alterações subsequentes. Hist. Educ. [Online] Porto Alegre v. 17 n. 41 Set./ dez. 2013 p. $103-122$
} 
Tabela 1

Frequência do ensino liceal e técnico (1919-1930).

\begin{tabular}{|c|c|c|}
\hline Anos lectivos & Ensino liceal & Ensino técnico \\
\hline $1919-1920$ & 13748 & 8820 \\
\hline $1920-1921$ & 13203 & 8892 \\
\hline $1921-1922$ & 12930 & 8832 \\
\hline $1922-1923$ & 13434 & 9452 \\
\hline $1923-1924$ & 14337 & 10078 \\
\hline $1924-1925$ & 15105 & 11756 \\
\hline $1925-1926$ & 16766 & 13016 \\
\hline $1926-1927$ & 18411 & 14446 \\
\hline $1927-1928$ & 19011 & 15812 \\
\hline $1928-1929$ & 17614 & 16521 \\
\hline $1929-1930$ & 17829 & 16391 \\
\hline
\end{tabular}

Fonte: Anuário Estatístico de Portugal, anos de 1923, 1924, 1925, 1927, 1928, 1929, 1930, e 1931. Lisboa: Imprensa Nacional.

A ascensão de Salazar e a institucionalização do Estado Novo trouxe, inicialmente, poucas alterações. A reforma de 1931, por exemplo, procurou simplificar o sistema e acentuar o carácter profissionalizante do ensino, embora procure também considerar novas actividades na definição dos cursos - comércio, vidro, mecânica, química e electricidade. Esta intervenção, ainda pouco consistente, teve também a ver com a existência de diferentes correntes de opinião dentro dos ideólogos educativos:

Em 1934, no Congresso da União Nacional manifestaram-se diferenças de concepção tanto da educação, como do próprio ensino técnico, sintomáticas da falta de uma posição oficial clara. De facto, em 1936, o novo Ministro da Instrução não pensava 0 ensino técnico como instrumento de desenvolvimento do país. (Cardim, 2005, p. 10)

Apesar de alguma indefinição, estabiliza-se o número de escolas: 52 em 1926, 47 em 1935, 51 em 1941, enquanto se assiste a um crescimento do quantitativo de alunos: cerca de 14.500 em 1926 e em 1942 perto de 35.500, o que se traduz numa "sobre-ocupação das instalações e numa sobre-exploração do débil equipamento das oficinas" (Cardim, 2005, p. 10).

Teremos de esperar pelo final da Segunda Guerra Mundial para se poder assistir a uma interessante mudança, em termos de filosofia do ensino técnico. No relatório da reforma de 1948, que já vinha a ser trabalhada por diferentes comissões desde o início da década de 1940, pode ler-se:

Uma longa tradição escolar de tipo abstracto leva certos sectores a subestimar o valor formativo do ensino técnico. No entanto, o operário devia também pensar e a pessoa culta trabalhar manualmente e assim, ambos seriam pessoas no melhor sentido. (Alves, 2009, p. 33)

Esta tentativa de valorizar a competência técnica aproximando-a da formação intelectual visava a antecipar a necessidade de o operário estar para além da força física e, 
sobretudo, assimilar e perceber a ideia de uma contínua valorização. Evidentemente que, no quadro da educação do Estado Novo, visava também a libertar os liceus da grande pressão em termos de população escolar e incentivar alunos a inscreverem-se nas escolas técnicas para se atingirem as metas económicas que vieram a ser definidas nos planos de fomento da década de 1950.

Há, no entanto, aspetos inovadores que marcarão o ensino técnico até à década de 1970:

a) reestruturação dos cursos em função dos setores económicos consultados pela equipa que a concebeu;

b) criação de um ciclo preparatório propedêutico que, apesar de politicamente justificado de forma ambígua ${ }^{9}$, resolveu a ligação ao primário e funcionará como antecâmara do alargamento da escolaridade obrigatória;

c) rede geograficamente mais abrangente - há mesmo localidades onde não há liceu oficial e existem escolas técnicas;

d) articulação entre os planos de fomento, os congressos da indústria portuguesa e a importância estratégica do ensino técnico.

O aumento do número de alunos, tabela 2, reflete um aumento da procura social deste tipo de ensino, sobretudo para aquelas camadas da população que tinham menos ambições educativas - foi sempre muito baixa a articulação entre o ensino secundário técnico médio e superior.

\section{Tabela 2}

Número de alunos do ensino técnico profissional.

\begin{tabular}{|l|c|c|c|c|}
\hline Ano/modalidade & 1930 & 1945 & 1960 & 1975 \\
\hline Ensino oficial & 18.375 & 43.037 & 98.227 & 120.183 \\
\hline Ensino particular & -- & 4.072 & 6.926 & 2.861 \\
\hline Total & 18.375 & 47.109 & 105.153 & 123.044 \\
\hline
\end{tabular}

Fonte: Alves, 2009, p. 34.

Conceptualmente há aspectos que importa salientar, tendo em vista o objetivo de enquadramento nas alterações mais amplas que se foram fazendo em termos mundiais. Por um lado, apesar de contido nas despesas destinadas à educação, o Estado Novo vai procurar manter com funções marcadamente distintas, o ensino secundário liceal e o ensino técnico, aproveitando os diferentes objetivos para ir reproduzindo as classes sociais de origem. Por outro, são já visíveis, sobretudo nos responsáveis pelo articulado das leis e nalguns decisores políticos, uma perspetiva mais ampla do papel, em particular, da escola técnica, uma vez que o liceu assumia-se literalmente como uma formação para elites.

9 "Em 1951, o ministro Pires de Lima afirma a vocação democratizante deste ciclo de estudos, 'a que mais rigorosamente se devia chamar primário superior ou complementar' para logo de seguida reconhecer que 'é preferível manter com carácter tendenciosamente técnico, nas escolas técnicas, esse ensino elementar, e com carácter tendenciosamente cultural, esse mesmo ensino, ou um ensino paralelo nos liceus'. Os reformadores sentem a necessidade de prolongar a escolaridade básica e de retardar a diferenciação dos percursos escolares. Mas as resistências a esta posição são muito fortes" (Alves, 2009, p. 33). 
Esta perspetiva não invalida que a participação do país em organismos internacionais e de políticos nesses debates torne cada vez mais próximos os papeis a desempenhar pelos dois subsistemas de ensino:

O sistema dual foi sendo posto em causa desde a década de cinquenta, apesar do discurso político tentar esconder esta realidade. [...] As medidas tomadas na década de sessenta, muito em especial a criação do ciclo preparatório do ensino secundário (graças à fusão do 1ํㅜ ciclo do ensino liceal e do ciclo preparatório do ensino técnico) prolongam esta lógica [...]. As propostas reformadoras de Veiga Simão são claramente portadoras de um processo de unificação do ensino. (Alves, 2009, p. 34)

O Despacho Ministerial de 25 de julho de 1973 tenta salvaguardar uma especificidade para o Ensino Secundário Técnico pelos Cursos Gerais e Complementares que contemplavam quatro sectores - agrícola, industrial, serviços e artes visuais - subdivididos em nove cursos gerais e 20 cursos complementares ${ }^{10}$. Mas a ausência de qualquer formação prévia de pessoal docente para especialidades e profissões tecnicamente exigentes, a par da ausência de um suporte orgânico que garantisse a ação ao longo do tempo, acrescido tudo isto da alteração política verificada em 1974, vai inviabilizar a implementação das mudanças e facilitar a fusão entre liceu e escola técnica, criando-se as novas escolas secundárias, com efeitos perversos e implicações significativas no organigrama do sistema educativo:

A unificação do ensino secundário teve algumas consequências no que diz respeito ao ensino técnico (agrícola, industrial e comercial), cujas instituições foram reestruturadas, perdendo as características de escolas que preparavam para a vida activa e transformando-se em escolas de tipo liceal. As circunstâncias em que se executou esta política deram origem a que ocorresse o que se poderá designar por um efeito perverso, que teve maior impacte do que a própria medida que lhe estava na origem, sobretudo porque a unificação do ensino secundário implicava um reforço das componentes técnicas e profissionais no ensino secundário complementar e mesmo no ensino superior não universitário, o que não veio a ocorrer se não muito mais tarde. (Grilo, 1994, p. 408)

Embora muitos tenham assumido este fim perverso, é um facto que a dinâmica discursiva sobre o papel do ensino técnico já vinha equacionando um outro sentido para a formação aí realizada. Em muitos países o papel planificador do Estado começou a ser posto em causa e o discurso sobre a planificação das necessidades de formação do capital humano cedeu o lugar à "formação aberta e polivalente, ao da valorização do desenvolvimento de novos perfis de competências, ao da validação das competências

${ }^{10}$ Cursos Gerais: Agricultura, Mecânica, Electricidade, Química, Construção Civil, Têxtil, Administração e Comércio, Formação Feminina e Artes Visuais. Cursos Complementares: Produção Agrícola, Produção Florestal, Produção Animal, Indústrias Agrícolas; Mecanotecnia, Electrotecnia, Radiotecnia, Quimicotecnia, Construção Civil, Topografia, Têxtil; Contabilidade e Administração, Informática, Distribuição e Mercados, Secretariado e Relações Públicas; Artes dos Tecidos, Equipamento e Decoração, Artes do Fogo, Artes Gráficas, Imagem.

ก. 41

Set./ dez. 2013

p. $103-122$ 
adquiridas no exercício da cidadania e no exercício profissional, ao da formação ao longo da vida" (Azevedo, 2000, p. 130). Começou-se a defender que a educação já não deve "subordinar-se a uma preparação para a vida, como algo exterior, que é moldado de fora (da economia) para dentro (aluno), mas como construção pessoal e social que se faz na vida "(lbid., p. 130). Estes novos enfoques que vão marcar, sobretudo, o último quartel do século 20 e a primeira década do 21 , já apareciam de forma mais ou menos explícita no discurso dos reformadores de meados do século passado. Por exemplo, na "Proposta de lei n. 99, apresentada pelo governo à Assembleia Nacional, sobre a reforma do ensino técnico profissional", que deu origem à reforma de 1948, pode ler-se no ponto 3 do preâmbulo justificativo:

A escola técnica diurna virá a ser aquilo que o desenvolvimento da vida económica portuguesa exige. Não se lhe peça, porém, como alguns inadvertidamente reclamam, o operário, o agente de trabalho altamente especializado, senhor de todos os segredos e particularidades da profissão. A escola, exactamente porque o é, nunca poderá levar a sua acção preparatória a tais extremos. Todas as autoridades no assunto reprovam os excessos prematuros de especialização na aprendizagem escolar [...]. O mérito da formação profissional obtida em circulo escolar [...] consiste em facilitar, por um lado, a rápida especialização posterior, e assegurar, por outro, ao jovem trabalhador a liberdade de escolher a sua profissão numa zona relativamente ampla de actividade. Esta é a sua melhor justificação como processo educativo. (Diário do Governo, 1947, p. 571)

São visíveis, neste excerto, alguns aspetos que são importantes no tempo longo do século 20, e em particular da segunda metade, já que estarão em discussão em diferentes fóruns nacionais e internacionais e determinarão os novos rumos da profissionalidade e o papel que a escola técnica, se não for subsumida num ensino secundário mais lógico e abrangente, terá neste contexto. Aliás, procurando identificar na Proposta traços que vão marcar a agenda dos debates educativos, é possível encontrar quatro linhas de pensamento que estarão presentes em múltiplos discursos e estudos.

Uma primeira, de transição com o que anteriormente era defendido, em que é ainda visível a indexação do papel do ensino técnico às necessidades de formação de mão-deobra. Numa situação de expansão económica, como aquela que se vai verificar até aos anos 1970, esta preocupação de resposta ao sistema económico no sentido de preparar o capital humano esteve presente, sobretudo nos países com uma situação económica capitalista em que mercados específicos ainda permitiam uma especialização sem grande concorrência situação próxima de um fordismo tardio.

Esta mesma situação pode também verificar-se em países recentemente descolonizados ou pouco desenvolvidos que funcionam, sobretudo, como fornecedores de produtos muito específicos para as economias já mais globalizadas ou, pelo menos, internacionalizadas. Este aspeto tanto pode ser constatado em Portugal - ainda com metas de desenvolvimento e fomento económico bem definidas pelo Estado e até com mercados coloniais protegidos -, como no Brasil, por exemplo, que o final da Segunda Guerra Mundial colocou na esfera de países mais desenvolvidos e onde o surto de desenvolvimento interno Hist. Educ. [Online] Porto Alegre v. 17 ก. 41 Set./ dez. 2013 p. $103-122$ 
passou pela crença do papel dos produtores profissionalizados num sistema de ensino que tinha a responsabilidade de os dotar das habilidades inerentes a uma mais eficaz produção. Não é por acaso que, neste período (1945-1970), o papel do ensino profissionalizante foi amplamente discutido ${ }^{11}$.

Uma segunda ideia defendendo que à escola não se deve pedir o mesmo que à antiga corporação, onde os segredos da profissão, a especialização, o exame e a autonomia de criação de uma oficina-loja significavam que o processo de aprendizagem tinha terminado, embora a melhoria da qualidade dos produtos fosse o garante de uma clientela permanente, mas não já de uma certificação social da sua capacidade. Esta ideia está associada à consciência que a Escola não pode fornecer tudo, não pode significar um processo terminal de aprendizagem, inferindo-se daqui que até pode ser contraproducente os excessos prematuros de especialização. Este problema foi central na discussão dos conteúdos que a escola devia então fornecer. Aliás, será esta linha de análise que nos trará até à fusão do ensino secundário e do ensino técnico e à definição do básico que a escola devia então ensinar - a formação geral, o back to basics ${ }^{12}$ ou a educação geral de nível conveniente.

Uma terceira, intimamente ligada à anterior, que assume claramente a escola como um local de passagem num determinado momento da vida, mas enfatiza o papel das especializações posteriores ou a possiblidade de a formação escolar abrir perspetivas profissionais numa zona relativamente ampla de actividade. Vai neste sentido o conceito de ensino técnico defendido numa das teses do $1^{\circ}$ Congresso Nacional do Ensino Técnico Profissional, realizado em 1958, quando se acentua que a escola técnica "não deve reduzir o aluno à condição de homo economicus à condição de homem máquina; o ensino técnico tal como o concebemos, afasta-se da noção simplista donde há apenas o escopo de formar técnicos especializados [...]; os caminhos são estes: formar o cidadão, o português, elevar o ensino profissional"13. Entroncar esta perspetiva no Relatório Delors, de 1996, e no princípio da educação ao longo da vida é realçar o aspecto antecipatório destas ideias.

Uma quarta em que é visível que, cada vez mais, se apelam aos organismos internacionais para legitimar posições e justificar decisões. Se, por um lado, significa a contextualização e a informação recolhida por quem decide, por outro esta ligação marcou toda a segunda metade do século 20 , quando a construção de modelos educacionais transnacionais estiveram nas agendas dos diferentes políticos, esperando da comunidade científica a sugestão ou indicação dos vectores que devem enformar as decisões internas. Se, numa primeira fase, meados do século 20 , essa ligação é de natureza informativa, à medida que avançamos na segunda metade do século a natureza prescritiva irá acentuar-se até ao limite de pôr em causa a possibilidade de qualquer decisão estritamente nacional. $O$

${ }^{11}$ Lei n. 5.692, de 11 de agosto de 1971, que alterou a LDB, instituiu directrizes e bases para a reforma do ensino do $1^{\circ}$ e $2^{\circ}$ graus e universalizou a educação profissional no ensino médio.

${ }_{12}$ Movimento de regresso ao que é fundamental, em que a formação geral é revalorizada e em que se atribui uma importância redobrada à formação nas áreas comportamentais, no fomento de atitudes e competências que derivam mais de uma profissionalidade geral do que de um perfil profissional especializado (Azevedo, 2000, e Reich, 1993).

13 1ํ Congresso Nacional do Ensino Técnico, dezembro de 1958. Tese da secção Cultura geral e formação técnica.

\begin{tabular}{|l|l|l|l|l|r|}
\hline Hist. Educ. [Online] & Porto Alegre & v. 17 & n. 41 & Set./ dez. 2013 & p. 103-122
\end{tabular}


Processo de Bolonha para o ensino superior, no contexto do espaço europeu, é também neste aspeto um bom exemplo de ponto de chegada.

Neste período de grandes transformações em Portugal e no mundo, marcado, sobretudo, pela Segunda Guerra Mundial, período de expansão económica até aos inícios dos anos 1970 e situação de recessão generalizada a partir daí, importa perceber o que se passou no Brasil à luz desta mudança generalizada, mas representando também a especificidade própria de um país em vias de desenvolvimento:

Até à década de 1930, dominou na administração escolar e nos meios pedagógicos primários, o princípio segundo o qual a educação secundária, que é um luxo aristocrático, deve ser abandonada pelo Estado à iniciativa particular [...]. Até ao início da década de 1940, a formação profissional praticamente se limitava ao treinamento operacional para uma produção em série e padronizada. [...] A Constituição brasileira outorgada pelo regime ditatorial do Estado Novo liderado por Getúlio Vargas, em 1937, previa (artº 129) a existência de escolas vocacionais e pré-vocacionais como um dever do Estado para com as classes menos favorecidas [...]. Essa determinação constitucional [...] possibilitou a criação em 1942 do Serviço Nacional de Aprendizagem Industrial (Senai) e, em 1946, do Serviço Nacional de Aprendizagem Comercial (Senac). Possibilitou ainda a organização da Rede Federal de Estabelecimentos de Ensino Industrial, tomando-se como base a antiga rede de escolas de aprendizes e artífices, que foram reaparelhadas para funcionarem como escolas técnicas federais. (Cordão, 2005, p. 46)

Com o fim da ditadura de Vargas, em 1945, e o desenvolvimento da industrialização no Brasil [...] a Constituição de 1946 estipula que o governo central deveria fixar as directrizes e bases da educação nacional. Um projeto educacional foi elaborado e, em 1948, enviado ao Congresso Nacional. Tal projeto, de cunho progressista, sofreu diversas vicissitudes, sendo arquivado, recuperado e emendado no Congresso durante 13 anos. (Zibas, 2005, p. 4-5)

A década de 1940 é, para o Brasil, um período particularmente importante em termos de decisões, mas também de compreensão do estádio de construção da identidade do ensino secundário/ensino médio em que se encontrava. Vários autores identificam este período como uma fase de passagem do treinamento, de cariz quase artesanal, para uma outra que respondesse melhor às solicitações de uma produção capitalista, ou nalguns casos ainda pré capitalista, mais padronizada e exigindo, portanto, um adestramento mais técnicoprofissional. Complementarmente, as expectativas criadas junto das camadas populares obrigaram alguns Estados a implementar um conjunto de "cursos secundários de primeiro ciclo (e mais tarde de segundo ciclo), noturnos, em prédios que durante o dia abrigavam cursos primários" (Zibas, 2005, p. 4-5), como é o caso de São Paulo logo em 1946.

A pressão para a frequência dos cursos profissionalizantes não invalida que se tenha desenvolvido, paralelamente, a defesa de uma política de equivalências com os ramos académicos, já que a simples frequência da Escola criava expetativas de se poder aceder/ascender a níveis superiores, objetivo concretizado com a lei federal n. 1.076/50, que "permitia que os concluintes de cursos profissionalizantes pudessem continuar seus estudos em níveis superiores, desde que provassem possuir o nível de conhecimento indispensável à 
realização dos requeridos estudos" (Cordão, 2005, p. 48). A plena equivalência entre todos os cursos de nível médio viria a ser, posteriormente, consagrada na Lei de Directrizes e Bases da Educação de 1961.

Ainda estamos na fase paternalista do Estado, reforçado face ao ambiente político em que se vivia, quando se esperava dele a implementação das medidas capazes de trazer 0 Brasil até ao caminho do progresso e do desenvolvimento pela via formativa profissionalizante da mão-de-obra. Naturalmente, procurou-se reformar com o mínimo de custos/investimentos - e daí o aproveitamento da antiga rede de escolas de aprendizes e artífices - o que nos fornece simultaneamente a ideia do estádio de desenvolvimento industrial e da delegação no Estado das funções até aí cumpridas por esses espaços de aprendizagem e certificação profissional.

Outro aspecto que ressalta, ainda, é a dificuldade da mudança. O período de estágio da proposta, cerca de 13 anos, evidencia os problemas, alguns deles históricos, na área educativa que provocaram acesas discussões: por exemplo, a força do lobby da Igreja Católica, o alcance do financiamento público, a difícil instabilidade entre o público e o privado - revelando as dificuldades que tiveram de ser superadas a nível interno para se conseguir algum consenso relativamente às diretrizes a implementar. Quando, finalmente, é publicada a lei federal n. 4.024, em 20 de dezembro de 1961, "o ensino secundário acolhia apenas 14\% daqueles que o procuravam e somente $1 \%$ dos estudantes alcançava o ensino superior" (Cordão, 2005, p. 48).

As alterações de natureza política da década de 1960 trouxeram um conjunto de consequências, tanto em termos de ruptura com o que se vinha implementando desde os anos 1940, como no que se refere à nova filosofia de enquadramento do ensino profissionalizante, sobretudo a nível interno, embora sofrendo também influências importantes de mediadores externos:

O golpe militar de 1964 interrompeu brutalmente todos os movimentos progressistas, inclusive aqueles na área da educação e, a partir desse mesmo ano, diversos acordos foram firmados com a Agência Norte-Americana para o Desenvolvimento Internacional (Usaid), o que submeteu a política educacional do país às determinações dos técnicos americanos. Em consonância com os assessores estrangeiros, Roberto Campos, ministro do governo militar, defendia em 1968, que o ensino secundário deveria perder suas características de educação humanista e ganhar conteúdos utilitários e práticos, atendendo ao povo, enquanto o ensino superior se destinaria, inevitavelmente às elites. (Zibas, 2005, p. 6)

Na sequência deste novo contexto, assistiu-se em 1971 à publicação de uma lei que teve grandes implicações no debate educativo brasileiro de finais do século 20 . A lei $n$. 5.692/71 dividiu o ensino não superior em dois graus: $01^{\circ}$ com a duração de 8 anos e 0 2ํำ com 3. Mas, sobretudo, considerou a profissionalização obrigatória. Os argumentos usados são ilustrativos, por um lado das opções económicas para o Brasil e, por outro, da filosofia que presidia ao novo ensino profissionalizante. Argumentava-se que havia necessidade de preparar o maior número de técnicos, dado o estreitamento das relações do país com o 
capital internacional e era dispensável a dualidade do sistema de ensino de nível médio. Era claro, também, o tom do aconselhamento internacional que, representativo de países num desenvolvimento pós-fordista e em processos de globalização, estavam interessados em manter alguns nichos de mão-de-obra barata e especializada para garantir, às suas multinacionais, meios de exploração de recursos existentes em países menos desenvolvidos ou técnicos capazes de exercer actividades extintas ou em vias de extinção nos países industrializados. Paralelamente, a filosofia de formação e as políticas educativas já caminham na senda de um neoprofissionalismo marcado por competências mais amplas e globais e menos técnicas.

As dificuldades posteriores evidenciaram a precipitação da medida, embora a sua existência não possa fazer esquecer as opções subjacentes.

Identifiquemos os problemas para podermos ter a noção das caraterísticas deste subsistema. Para começar, a massificação dos cursos profissionalizantes nas escolas secundárias não podia ser acompanhada pelo volume de investimentos necessários, sobretudo em equipamentos. Depois, o simples confronto com os antigos cursos técnicos de nível médio ridicularizou a formação que se passou a fazer, fosse no confronto das instalações, fosse na qualidade dos professores, fosse no resultado formativo dos alunos ou, finalmente, na desconfiança com que passaram a ser percebidos pelo tecido empregador. Naturalmente, a massificação arrastou consigo um nivelamento por baixo com um distanciamento ainda maior entre as escolas públicas e as privadas que, apesar das medidas tomadas, procuraram manter o nível de qualidade anterior, importando-se pouco com a nomenclatura ou designação dos cursos, mas apostando, sobretudo, no conteúdo.

Evidentemente que acabou por se reconhecer o equívoco e em 1982 assumiu-se o fracasso da iniciativa permitindo, pela lei n. 7.044, que essa formação deixasse de ser obrigatória, mas uma opção a tomar por cada escola. O regresso à democracia, em 1985, permitiu outro enquadramento das questões educativas, assegurou uma nova visão para os diversos graus de ensino consagrados, sobretudo, na LDB de 1996, e aproximou mais as discussões e decisões brasileiras das análises que, por essa altura, já se faziam há algum tempo no quadro das grandes organizações internacionais.

As últimas décadas do século 20 e a primeira do século 21 trouxeram para a ribalta das discussões educativas novas temáticas que vão definitivamente marcar os novos rumos que o ensino técnico terá de assumir, tanto em Portugal num quadro europeu, como o Brasil em contexto americano, um e outro num espaço global internacional.

\section{Referências}

ALVES, Luís Alberto Marques; SOUSA, Pedro Rodrigues de; MORAIS, Teresa Torrinhas; ARAÚJO, Francisco Miguel Veloso. Ensino técnico (1756-1973). Lisboa: Secretaria Geral do Ministério de Educação, 2009.

ARROYO, António José. Relatórios sobre o ensino elementar industrial e comercial. Lisboa: Imprensa Nacional, 1911. 
AZEVEDO, Joaquim. O ensino secundário na Europa: o neoprofissionalismo e o sistema educativo mundial. Porto: ASA, 2000.

CARDIM, José Eduardo de Vasconcelos Casqueiro. Do ensino industrial à formação profissional: as políticas públicas de qualificação em Portugal. Lisboa: Universidade Técnica de Lisboa, 2005.

COLECÇÃO OFICIAL DE LEGISLAÇÃO PORTUGUESA. Ano 1898. Lisboa: Imprensa Nacional, 1899.

CONSELHO NACIONAL DE EDUCAÇÃO. O ensino secundário em Portugal. Lisboa: CNE, 1999.

CORDÃO, Francisco Aparecido. A educação profissional no Brasil. In: AAVV. Ensino médio e ensino técnico no Brasil e em Portugal: raízes históricas e panorama atual. Campinas: Autores Associados, 2005, p. 43-110.

DIÁRIO DO GOVERNO. Proposta de lei n. 99, apresentada pelo governo à Assembleia Nacional, sobre a Reforma do Ensino Técnico Profissional. In. Diário do Governo, la série, n. 139, 19 jun., 1947.

FOSTER, Philip J. The vocational scholl fallacy in development planning. In: KARABEL, Jerome; HALSEY, A. H. Power and ideology in education. New York: Oxford University Press, 1978, p.125-176.

GRILO, E. Marçal. O sistema educativo. In: REIS, António (coord.). Portugal: 20 anos de democracia. Lisboa: Circulo de Leitores, 1994, p. 406-435.

HUFNER, Klaus; MEYER, John W.; NAUMANN, Jens. Investigación sobre política educativa comparada : perspectiva de la sociedad mundial. Revista de Educación, n. 297, 1992, p. 347402.

MEYER, John W; RAMIREZ, Francisco O; SOYSAL, Yasemin N. World expansion of mass education, 1870-1980. Sociology of Education, n. 65, 1992, p. 128-149.

PEREIRA, Miriam Halpern. Artesãos, operários e o liberalismo: dos privilégios corporativos para o direito ao trabalho (1820-1840). Ler História, n. 14, Lisboa: Teorema, 1998, p. 41-86.

RODRIGUES, Manuel Ferreira; MENDES, José M. Amado. História da indústria portuguesa: da idade média aos nossos dias. Lisboa: AIP/Publicações Europa América, 1999.

TROGER, Vincent (2006). La formation professionnelle des jeunes en question. Disponível em : $<$ www.scienceshumaines.com/index.index.article $=3330>$. Acesso em: 7 out., 2006.

ZIBAS, Dagmar M.L. Breves anotações sobre a história do ensino médio no Brasil e a reforma dos anos de 1990. In: AAVV. Ensino médio e ensino técnico no Brasil e em Portugal: raízes históricas e panorama atual. Campinas: Autores Associados, 2005, p. 17-42. 
LUIS ALBERTO MARQUES ALVES é professor associado com agregação da Faculdade de Letras da Universidade do Porto. Investigador do Citcem/Flup e colaborador da Unidade de Investigação do Instituto de Educação de Lisboa. Endereço: Via Panorâmica s/no - 4150-564 - Porto - Portugal.

E-mail: laalves@letras.up.pt.

Recebido em 29 de novembro de 2012. Aceito em 27 de março de 2013. 